\title{
Propedêutica à epistemologia do método em educação e a dialética da protoforma do lugar do discurso
}

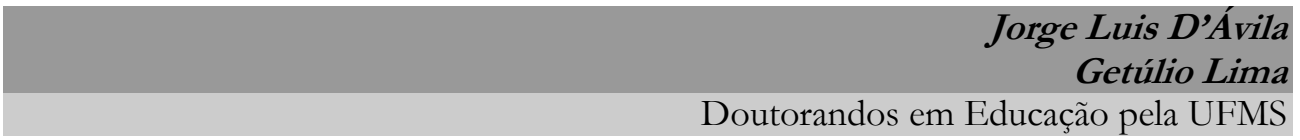

\begin{abstract}
Resumo
O artigo possui como temática central o estudo sobre a questão do método e a pesquisa em educação, sob a ótica do materialismo histórico - dialético. O método que caracteriza uma ciência revela seu modus operandi e de apreensão de uma determinada realidade. Suas categorias são "formas de ser" e "determinações de existência", em que sua prática e suas atividades, tanto no campo ético, político, cientifico e pedagógico, estão conectadas holisticamente a um modo de sociabilidade engendrada historicamente. A pesquisa em educação não se limita a manipulação de uma quantidade de dados empíricos disponíveis para a construção de práticas educativas de assimilação de esquemas operatórios e a formação de hábitos miméticos, mas que crie suportes e mecanismos que possibilitem desencadear processos e a criação de situações problematizadoras que estimulem a ação nas diferentes formas da realidade, na produção do conhecimento científico são utilizadas categorias de análises constitutivas das teorias, bem como, métodos e técnicas para o estudo de um dado objeto de pesquisa, que "nada mais é do que um reflexo que expressa o grau de consciência do homem em relação ao desenvolvimento material".

Palavras-chave: método; educação; epistemologia.
\end{abstract}

\begin{abstract}
The article has as its central theme the study of the question of the method and research in education, from the perspective of historical materialism dialectical. The method featuring a science reveals their modus operandi and seizure of a certain reality. His "categories are ways of being" and "determinations of existence", where his practice and its activities, both in the ethical, political, scientific and educational, are holistically connected to a mode of sociability engendered historically. Research in education is not limited to handling an amount of empirical data available for the construction of educational assimilation schemes operative mimetics and habit formation, but that creates and supports mechanisms that allow triggering processes and the creation of problem-solving situations that encourage action in different forms of reality, the production of scientific knowledge are used analytic categories constitutive theories as well as methods and techniques for the study of a particular object of research, which "is nothing more than a reflection that expresses degree of consciousness of man in relation to material development.
\end{abstract}

Keywords: method; education; epistemology. 
Toda verdad es una verdad del conocimiento [...] es decir, la formación de la verdad, proceso que constituye la formación de los fenómenos del espíritu como fenómenos del conocimiento.

G.Kursánov

\section{Introdução}

ste artigo é o resultado das discussões realizadas nas aulas de
Seminário de Epistemologia da Pesquisa em Educação, do curso
de doutorado do programa de Pós-graduação mestrado e doutorado da Universidade Federal de Mato Grosso do Sul (UFMS).

Essa disciplina foi essencial para a compreensão das questões relativas ao método e dialogar com diferentes visões do campo científico, entre eles, o método positivista, fenomenológico, hermenêutico e o materialismo histórico e dialético.

Partimos do pressuposto que a ciência deve revelar o modus operandi e de apreensão de uma determinada realidade, bem como, a natureza das condições sociais de existência. Os elementos constituintes de um método de pesquisa e suas "categorias são formas de ser" e "determinações de existência", em formas de ser social, em que sua prática e suas atividades, tanto no campo ético, econômico, político, cientifico e pedagógico, estão conectadas holisticamente a um modo de sociabilidade engendrada historicamente.

Entendemos que as categorias que sedimentam o processo de apreensão de um dado momento histórico e realidade passam pela forja dos antagonismos das diferentes classes sociais e não meramente pela busca e anseio de separação de juízo de fatos e juízo de valor.

O método materialismo histórico e dialético nos permitirá compreender nossos objetos, pois o mesmo parte do ser social, da formação histórico-social, da unidade orgânica das forças produtivas e das relações de produção e suas contradições. A matéria prima desse método é o movimento 
concreto-real (os objetos existentes na realidade), o concreto-pensado (conhecimento dos objetos, apropriação cognitiva do real) e os processos da estrutura da prática social em uma totalidade articulada. As "formas de situação de qualquer problema" e seus conteúdos, que compõe a problemática das teorias, são resultados da protoforma do lugar do discurso.

Esse método de interpretação da realidade desenvolveu-se a partir das formulações de Karl Marx (1818 - 1883) e Friedrich Engels (1820-1895). Esta metodologia ancora-se em uma concepção que tem na relação entre teoria - prática e a visão crítica das relações sociais e sua fundamentação.

A realidade em seus diversos aspectos é extensivamente exuberante e dialética. Como matéria das ciências, esse objeto é ordenado e classificado de acordo com conveniências e interesses de pesquisa, de um determinado momento histórico, econômico e social. Cada ciência seleciona seus elementos de pesquisa, não de forma cega e contingente, em especial nas ciências sociais, mas conforme as conexões dialéticas entre singular, particular e universal determinada.

A forma de indagação de um determinado problema, em certa medida, formula a intenção da resposta. A problemática da investigação, a seleção do objeto de estudo, a interpretação dos fatos, a classificação do essencial e do sem importância, manifesta a visão do mundo e o lugar do discurso.

A ciência se faz necessária, parafraseando Marx, por que, se aparência e essência coincidissem, seriam desnecessárias a pesquisa e a atividade de estudo. O mosaico das relações essenciais não está exposto nas relações fenomênica-aparência. Requer o esforço de superação do encanto do halo do imediato e da certeza da superficialidade empírica.

Qual é o conceito de pesquisa? Uma pesquisa se torna diferente de acordo com o aporte teórico metodológico? Que pontos são explicitados ou silenciados da realidade por determinado método de pesquisa? É possível que as opções de pesquisa sejam instrumentos teóricos de hegemonizar o ponto de vista de uma classe social, em seus aspectos políticos, culturais, econômicos e espirituais? 
A ciência é um sistema especializado do saber. Necessitamos conhecer o lugar e rastrear o processo histórico de seu desenvolvimento, inquirir nas estruturas categoriais da consciência dos pesquisadores como expressão auto-consciente desta ciência, as mudanças das relações socioeconômicas, políticas e ideológicas, bem como, suas interconexões conceituais teóricas e metodológicas (LÖWY,1987). Suas contribuições para a produção da verdade, a qual depende do "interesse que se tem em saber e em fazer saber a verdade (ou inversamente, em ocultá-la ou ocultá-la de si" (LÖWY, 1987, p. 208).

Sendo assim, cabe o exercício de discutir a respeito dos métodos citados anteriormente para que possamos reafirmar que o método que responde aos nossos anseios educacionais e busca de respostas aos problemas das relações sociais no contexto da sociedade atual encontram sua base nos estudos iniciados por Marx e Engels.

\section{Propedêutica à Epistemologia do Método em Educação}

Muitos teóricos especialistas em metodologia científica consideram a pesquisa como sendo aquilo que pode ser quantificado, traduzido em números, opiniões, informações de forma que classifique e analise um objeto utilizando técnicas específicas (percentagem, média, mediana, desvio-padrão, coeficiente de correlação, análise de regressão). Sendo esses dados, para esses especialistas, elementos suficientes para o entendimento do objeto de estudo.

Essa perspectiva teórica é própria do método positivista, método que não possui características revolucionárias, conservador, que considera os fatos sociais como coisas cuja natureza, por mais flexível e maleável que seja, não é, porém, modificável pela vontade do homem.

O positivismo se apresenta como uma ciência e uma proposição para os problemas da sociedade. Por ser ciência, é "positivo", e como tal, um instrumento político de combate das teorias negativas, criticas, destrutivas, subversivas e revolucionárias, como da revolução francesa e do socialismo. 
Para Löwy (1987), a figuração "ideal-típica” do positivismo pode ser dito em três ideias principais: primeira é a hipótese fundamental do positivismo: "a sociedade humana é regulada por leis naturais", leis invariáveis, independentes da vontade e da ação humana, como a lei da gravidade ou do movimento da terra em torno do sol, de modo que na sociedade reina "uma harmonia semelhante à da natureza, uma espécie de harmonia natural" (LÖWY,1987, p. 17).

A segunda hipótese decorre da primeira, para o positivismo, a conclusão epistemológica de que "a metodologia das ciências sociais tem que ser idêntica à metodologia das ciências naturais, posto que o funcionamento da sociedade é regido por leis do mesmo tipo das da natureza" (LÖWY,1987, p. 17).

A terceira ideia básica do positivismo, talvez a de maior consequência, reza que da mesma maneira que as ciências da natureza são ciências objetivas, neutras, livres de juízos de valor, de ideologias políticas, sociais ou outras, as ciências sociais devem funcionar exatamente segundo esse modelo de "objetividade científica". Ou seja: o positivismo afirma a necessidade e a possibilidade de uma ciência social completamente desligada de qualquer vínculo com as classes sociais, com as posições políticas, os valores morais, as ideologias, as utopias, as visões de mundo, pois este conjunto de opções são prejuízos, preconceitos ou prenoções que prejudicam a objetividade das Ciências Sociais (LÖWY,1987, p. 17-20).

Para os positivistas, um dos instrumentos para se alcançar a objetividade científica é através da neutralidade axiológica. Os ideais naturais do positivismo têm sua origem no combate intelectual do Terceiro Estado contra a ordem feudal-absolutista. Já o positivismo moderno nasceu como um legítimo descendente da filosofia do Iluminismo. Condorcet, ao defender o positivismo, tinha como objetivo confesso o de emancipar o conhecimento social dos "interesses e paixões" das classes dominantes.

De acordo com Löwy (1987), Condorcet ((1743 - 1794), Comte (1798-1857), Popper (1902-1994) e outros teóricos, são fundamentalmente positivistas: eles tentam fundar a sociologia do conhecimento sobre fatos e 
dados, pretendem lidar com realidades humanas com a mesma isenção e a mesma objetividade com que observariam coisas, ou então se dispõe a exorcizar os juízos de valores no exame de questões em face das quais nunca podemos ser neutros.

O axioma da neutralidade valorativa das ciências sociais conduz, logicamente, o positivismo, a negar o condicionamento histórico-social do conhecimento. A própria questão da relação entre conhecimento científico e classes sociais geralmente não é colocada: é uma problemática que foge ao campo conceitual e teórico do positivismo.

Para essa corrente filosófica, a sociedade pode ser epistemologicamente assimilada pela natureza, e ser estudada pelos mesmos métodos, démarches e processos empregados pelas ciências da natureza. A sociedade se explica pelo estudo da natureza. As ciências da sociedade, assim como as da natureza, devem limitar-se à observação e à explicação causal dos fenômenos, de forma objetiva, neutra, livre de julgamentos de valor ou ideologias, descartando previamente todas as pré-noções e preconceitos.

Oliveira (2010) denomina esse método de "pedagogia do consenso", hegemônico nas pesquisas do início século XX, utilizada para a construção do ideário burguês, principalmente com a apropriação da filosofia política liberal de John Locke fundador da teoria da "tabula rasa". Não há uma distinção entre as ciências humanas e as ciências naturais, há um espaço cognitivo de intermediação, ou seja, uma zona de transição que as relaciona (LÖWY 1987).

Cabe considerar que não desconhecemos, negamos, desqualificamos ou menosprezamos os aspectos científicos apresentados por esse paradigma. A questão é compreender sua configuração histórica e social, [...]

\footnotetext{
' [...] coloca todos os homens na vala comum. Como o homem, ao nascer, é uma folha de papel em branco, rei ou escravo, rico ou pobre, simplório ou gênio, todos começam a vida no mesmo ponto. As diferenças vão surgindo pelas suas experiências e pela educação que recebem. É, portanto uma questão de esforço individual (OLIVEIRA, 2010 , p. 30).
} 
compreender a sua origem, a sua natureza e a função que cada um deles exerceu ou exerce na reprodução do ser social (TONET, 2013, p. 10).

Desta forma, um objeto de estudo na proposta liberal pode até nos revelar detalhes de grande monta, no sentido de compreender sua implantação nesse momento histórico. Sobretudo, esse método não nos permite realizar nexos do singular e universal, pois entendemos que a educação não é uma questão particular e sim, que ela, para se materializar, depende das determinações universais. “[...] O singular é a manifestação, no espaço convencionado, de como leis gerais do universal operam dando-lhe uma configuração específica" (ALVES, 2003, p.29). Assim, as categorias científicas universal e singular, devem estar presentes em todos os ensaios de investigação, sob a premissa de recusar o:

[...] teor de cientificidade a qualquer elaboração que omita uma ou outra e, principalmente, a relação entre ambas. Se o singular é a forma singular de realização do universal, só iluminado pelo universal e através dele pode conter elementos que contribuam para cimentar a identidade de um objeto de estudo (ALVES, 2003, p.29).

Essas explicações de Alves (2003) estão ausentes, também na concepção teórica da fenomenologia, esse método se dá por meio de um processo de redução do mundo a um objeto concebido. Segundo Reale e Antiseri (2006), a fenomenologia é um método para "voltar às próprias coisas" e consiste em uma suspensão provisória dos nossos valores, julgamentos e pré-conceitos no processo de apreensão do objeto estudado (fenômeno), a fim de compreender a realidade tal como ela é tal como ela aparece à consciência.

O mundo que aparece é aquele do sentido de cada um, esse é sua essência. O mundo agora não é mais o que dizem que ele é, mas o que aparece à consciência. A Fenomenologia não explica, ela descreve a realidade; o real só existe quando um sujeito concebe sua existência e lhe doa sentido. Como método, ela não permite generalizações, pois a descrição 
do percebido é para a consciência de quem a descreve (REALE, ANTISERI, 2006, P. 175-177).

A Fenomenologia é a descrição de todas as essências dos fenômenos. “o que importa, no entanto, é descrever o que efetivamente se dá à consciência, o que nela se manifesta e nos limites em que se manifesta" (REALE, ANTISERI, 2006, P. 182).

Esse método é o positivismo ao avesso, é a busca da "neutralidade" do positivismo pelo "enigma da visão" que pretende ver a realidade tal qual ela aparece à consciência, livre de pré-conceitos e teorias pré-existentes.

Como nos esclarece Tonet (2013) essa abordagem metodológica não esclarece que um problema pode ser abordado levando em consideração dois pontos de vista: gnosiológico ${ }^{2}$ ou ontológico ${ }^{3}$. Esse esclarecimento não ocorre pois nessa concepção não existe dois caminhos. Ela parte do pressuposto de que essa abordagem é única e correta, “[...] sua apresentação é sua própria justificação" (TONET, 2013, p. 11).

A nosso ver, este modo de abordagem falseia o tratamento da problemática do conhecimento, pois impede que se veja a existência de outros caminhos. Impede, portanto, a formação de uma mentalidade realmente crítica. Ora, se levarmos em conta o conhecimento é sempre, imediata ou mediatamente, um instrumento para a intervenção social, então, não há dúvida, de que isso tem largas conseqüências sociais que permeiam a construção da cientificidade. (TONET, 2013, p. 11).

Já em relação à hermenêutica ela possui conceitos fundamentais que são os sentidos, a compreensão e a interpretação. Da articulação desses conceitos, surgem as regras ou os princípios básicos da hermenêutica

\footnotetext{
2 Segundo Tonet (2013, p. 12) "gnosiologia é o estudo da problemática do conhecimento. Nesse caso, portanto, o conhecimento é o objeto a ser estudado, assim como poderia ser qualquer objeto. Deste modo, o próprio conhecimento Ignosis, em gregol pode ser abordado de um ponto de vista gnosiológico ou de um ponto de vista ontológico."

3 "A ontologia é o estudo do ser, isto é, a apreensão das determinações mais gerais e essenciais daquilo que existe. A ontologia pode ter um caráter geral, quando se refere a todo e qualquer existente ou um caráter particular, quando diz respeito a uma esfera determinada do ser, como por exemplo, o ser natural ou o ser social. (TONET, 2013, p. 121
} 
(PAVIANI, 2006). Nesse pressuposto teórico, existe um vasto mundo “[...] para interpretar e entender: gestos, ações, projetos, traços e testemunhos de ideias. [...] Uma coisa é uma doação de sentido e outra coisa, bem diferente, é uma interpretação do sentido encarnado em um objeto" (REALE, ANTISERI, 2006, p. 265). Desta forma, a hermenêutica, é entendida como a percepção do individuo que se converte em seu ponto de partida e constituição de seu mundo de ações.

Feito esse exercícios de entendimento de diferentes metodologias que estão sendo aplicadas nas pesquisas em educação, se faz importante esclarecer o leitor do porque da escolha do materialismo histórico dialético como método que irá dar concretude as nossas teses.

Assim, como Löwy (1987), acreditamos que o marxismo dá um passo a mais dos métodos analisados anteriormente. Para o materialismo, o conhecimento da realidade social é um instrumento político que pode orientar os grupos sociais na luta pela transformação da sociedade. É no terreno da prática que se deve demonstrar a verdade da teoria. Pois, comenta o autor em questão, segundo Marx, Lênin e Rosa Luxemburgo, as lutas de classes não podem ser compreendidas senão em relação com a história social e econômica, tudo se passa no movimento histórico do concreto e que uma sociedade verdadeira é composta de classes com interesses particulares e concepções diferentes.

Desta forma, “[...] a história de todas as sociedades até hoje é a história das lutas de classes" (MARX e ENGELS, 1998 p.4). As classes sociais são os sujeitos fundamentais da história. Pois, é em torno da luta pela produção e apropriação de seus meios que se desdobra, direta ou indiretamente, o processo social.

É a partir de sua consciência de classe que o proletariado pode tomar o poder e transformar a sociedade em socialista por meio do conhecimento objetivo da realidade, da estrutura econômica e social, da relação de forças e da conjuntura política. A visão de mundo proletária representa o horizonte comum a um conjunto de forças políticas e intelectuais, sociais e culturais que reivindicam sua utopia revolucionária. É preciso conhecer a estrutura de 
categorias da consciência do pesquisador que define os fatos sociais de acordo com suas aspirações, interesses e posição de classe (LÖWY, 1987).

Além das questões sociais e segundo Bourdieu (2004) é preciso também ter atenção para o fato da ilusão do saber imediato. Este é o ponto de partida na construção do objeto científico. Para vencer este primeiro obstáculo epistemológico, é necessário um processo de ruptura, de inquirição das formas de pensar e dos pensamentos sobre as relações sociais, considerando-o dentro das condições sociais que o produzem, para isso é necessário engendrar verdadeiros "hábitos intelectuais" que conduzam à busca contínua e incessante da construção do conhecimento científico do social.

Durante nossas vidas, enquanto seres humanos submetidos a uma prática social, estamos diante de várias questões e temas que estão no nosso dia-a-dia, nas nossas relações familiares, de amizades, nos jornais, nas revistas etc. Temas como violência, miséria, exclusão social, justiça, democracia, exploração, classes sociais, etc., Estes temas, ao serem debatidos por pessoas no seu cotidiano refletem o que Bourdieu (2004) caracteriza como se cada indivíduo se sentisse "um pouco sociólogo". Entretanto, o pesquisador, neste contexto, deve estar atento a tentação da lógica do "achismo".

Pelo contrário, o pesquisador deve manter-se em um constante estado de vigilância científica sobre a influência que o senso comum exerce sobre ele, pois, a vida cotidiana é uma experiência muito próxima do pesquisador e isto gera um enorme obstáculo a ser enfrentado. Este senso comum deve ser combatido pelo pesquisador na sua análise, pois ele pode ter uma leitura diferente do fato a que ele está submetendo o seu esforço interpretativo. O esforço deve-se orientar pela busca da aproximação das relações objetivas e não simplesmente das representações dos indivíduos sobre seu mundo. Nesse sentido,

O princípio da não-consciência impõe que seja construído o sistema das relações objetivas nas quais os indivíduos 
se encontram inseridos e que se exprimem mais adequadamente na economia ou morfologia dos grupos do que nas opiniões e intenções declaradas dos sujeitos. Não é a descrição das atitudes, opiniões e aspirações individuais que tem a possibilidade de proporcionar o princípio explicativo do funcionamento de uma organização, mas a apreensão da lógica objetiva da organização é que conduz ao princípio capaz de explicar, por acréscimo, as atitudes, opiniões e aspirações (BOURDIEU, 2004, p. 29).

Essa é uma condição "sine qua non” da construção científica, o da não consciência, uma forma de vigilância contra o psicologismo que reduz todos os fatos sociais a fenômenos de interação entre pessoas, dotados de forte conteúdo de motivações. Em suma, a vigilância determinada e consciente contra os reducionismos dos fatos sociais a meros epifenômenos antropológicos e psíquicos. Essa atitude científica implica na submissão dos procedimentos metodológicos a uma razão epistemológica cética, questionadora e vigilante.

Semelhante tarefa, propriamente epistemológica, consiste em descobrir no decorrer da própria atividade científica, incessantemente confrontada com o erro, as condições nas quais é possível tirar o verdadeiro do falso, passando de um conhecimento menos verdadeiro a um conhecimento mais verdadeiro (BOURDIEU, 2004, p.17).

Para o efeito desta atitude é preciso "intensificar a dialética da razão e da experiência"

Toda experiência bem construída tem como efeito intensificar a dialética da razão e da experiência, mas somente com a condição de que o pesquisador saiba pensar, de forma adequada, os resultados, inclusive negativos, que ela produz e se interrogue sobre as razões que fazem com que os fatos têm razão de dizer não (BOURDIEU, 2004, p.78). 
Todo conhecimento sobre a realidade social tem um caráter social, isto é, é ele próprio um produto social. É fundamental interrogar sobre as condições de validade de um conhecimento científico sobre a sociedade, e em particular sobre as relações entre o saber do investigador social e o dos próprios sujeitos sociais.

A atividade científica como uma prática social específica, que recorre a determinados meios de trabalho e que se desenvolve num contexto social e histórico, sendo influenciada, portanto, para além das condições teóricas, pelas condições econômicas, políticas e ideológicas da sociedade onde se insere. Considerando-o dentro das condições sociais que o produzem, criando no cientista verdadeiros "hábitos intelectuais" que conduzam à busca contínua e incessante da construção do conhecimento científico do social.

A vigilância epistemológica, aqui se faz extremamente necessária, ao processo de se explicitar e distinguir os meios de investigação científica (teorias, métodos e técnicas), e assumindo uma postura racionalista da ciência, tendo sempre a preocupação que "a ciência não é a captação ou captura do real, mas uma certa postura e organização intelectual com a qual 'é possível ter a segurança de nos aproximarmos do real' (BOURDIEU, 2004, p. 105).

Para Marx a realidade social é um processo histórico, não é simplesmente um conjunto de relações ou conglomerado de coisas, é antes o processo de transformação inerente a um determinado conjunto de relações. É a ação humana responsável pelas modificações sociais. Na Ideologia Alemã, Marx (1968) expõe os passos e as premissas de interpretação da sociedade:

Las premisas de que partimos no tienen nada arbitrario, no son ninguna clase de dogmas, sino premisas reales, de las que sólo es posible abstraerse en la imaginación. Son los individuos reales, su acción y sus condiciones materiales de vida, tanto aquellas con que se han encontrado como las engendradas por su propia acción... El modo como los hombres producen sus medios de vida 
depende, ante todo, de la naturaleza misma de los medios de vida con que se encuentran y que se trata de reproducir (MARX, 1968, p. 19).

Marx adota um método de "aproximações sucessivas", passando dos fenômenos mais abstratos para o mais concreto como um meio de “desnudar" suposições simplificadoras da realidade e que mascaram as fontes reais dos problemas sociais, econômicos, políticos, educacionais, entre outros.

A sociedade, segundo o prisma marxista, é um sistema de atividade humana que funciona mediante relações entre pessoas, ou, de modo similar, que é um sistema de relações no qual os indivíduos executam e intercambiam suas atividades. De acordo com Marx (1979, p. 91) na "Miséria da Filosofia", a "maneira de ganhar a vida" afeta as relações sociais, os princípios e as ideias das pessoas. "Los hombres, al establecer las relaciones sociales con arreglo al desarrollo de su producción material, crean también los principios, las ideas e las categorías conforme a sus relaciones sociales" (MARX, 1979, p. 91).

Assim, se entende que a base social, a sua formação, suas instituições e regras de funcionamento, suas ideias, seus valores devem-se às condições materiais. E, é a partir delas que se constrói a sociedade e, somente a compreensão dessas condições permite o entendimento e a possibilidade de transformação.

\section{A realidade e a educação na perspectiva do materialismo histórico e dialético}

Seguindo as premissas do materialismo histórico e dialético, se entende que a pesquisa deve entender que a educação é um projeto político e ideológico de uma sociedade em determinadas condições materiais e em um dado momento da história. Por isso,

O estudo da história da educação é fundamental para se compreender as relações de poder e os mecanismos de 
relação entre Estado e sociedade civil, o papel do Estado e sua representatividade, o modelo educacional para os trabalhadores e o modelo desenvolvido para as elites, além de possibilitar o entendimento de que a educação não é uma atividade neutra, mas se desenvolve no sentido de atender às necessidades de determinados grupos (FEDATTO, 2011, s/p).

A educação, atualmente, é colocada como uma questão fundamental para os homens neste novo século, o que pode ser percebido pela permanência constante do tema da educação nos meios de comunicação, propagandas governamentais, bem como em pesquisas e encontros acadêmicos. O paradigma hegemônico hoje é o do mercado total. Nesse caso é o mercado a instituição central do sistema e o Estado é um instrumento de poder econômico.

O Estado se caracteriza por ser um produto determinado pelas relações de produção marcadas pela propriedade privada. Segundo Marx (2010, p. 59-60), “[...] o Estado e a organização da sociedade não são, do ponto de vista político, duas coisas diferentes", ao contrário, "o Estado é o ordenamento da sociedade", uma vez que ele, o Estado, "repousa sobre a contradição entre vida privada e pública, sobre a contradição entre os interesses gerais e os interesses particulares." É o colaborador mais valoroso do capital.

Dessa forma, esse instrumento a favor da burguesia se utiliza de várias instâncias, dentre elas a educação para cumprir o papel que lhe cabe como aparato institucional da ordem burguesa e garantir o poder de classe. A educação, como uma das atividades necessárias à construção da vida social, situa-se na trama de mediações que a entrelaçam ao complexo da sociedade de classes.

Vianna (1976) alerta-nos que, na sociedade contemporânea, delimitar os conceitos de "esfera pública" e de "esfera privada" requer certo cuidado, pois, na sociedade capitalista, fundada na propriedade privada dos meios de produção, o público é sempre, ainda que de modo contraditório privado. Trata-se, com efeito, de apresentar os interesses privados (da classe 
dominante) como expressão 'genuína' do interesse público (do conjunto da sociedade). Em outras palavras, trata-se de organizar o poder privado (de uma classe) na forma de poder público (o Estado), que segundo Engels (1982, p. 193)

[...] nasceu da necessidade de conter o antagonismo das classes, e como, ao mesmo tempo, nasceu em meio ao conflito delas, é, por regra geral, o Estado da classe mais poderosa, da classe economicamente dominante, classe que, por intermédio dele, se converte também em classe politicamente dominante e adquire novos meios para a repressão e exploração da classe oprimida.

O próprio Estado democrático de direito, nessas circunstâncias, se conserva, segundo Vianna (1976), por meio de um "pacto democrático" e pela intermediação de instituições de "tamanho médio", que aproximam os cidadãos da política estatal. A lei introduz a noção de que a força de trabalho não pertence ao âmbito do privado, achando-se tutelada pelo Estado e sujeita as suas razões. Desta forma

[...] a sociedade e o mercado de trabalho em particular são recobertos pela legislação, com o fim de solidarizar seus componentes num todo orgânico, incapazes isoladamente de conviverem em harmonia. Tudo que é privado se reveste de um caráter público, conformando um ramo do direito que se pretende autonomizar das relações mantidas pela sociedade civil. Como isso, impede-se a percepção da sociedade como um mercado, embora legitime-se o indivíduo possessivo (VIANNA, 1976, p. 29).

Segundo Vianna (1976, p. 23) "a classe trabalhadora, ao se organizar e reivindicar por direitos sociais, denuncia a forma mercantil do modo de produção capitalista" e a "igualdade formal a todos estendida não decorre de uma igualdade real". Neste contexto "a sociedade civil como o reino da necessidade, em que os indivíduos isolados e apetitivos competem animosamente em torno de bens escassos, a 'produção do público' aparece como algo a ser elaborado" (VIANNA, 1976, p. 13) para além do capital, 
apreendendo o movimento dialético que nos coloca o prelúdio da superação histórica desta formação social ditada pelos valores do capital, assevera Mészáros (2005), tendo em vista o fato de que o processo de reestruturação radical deve ser orientado pela estratégia de uma reforma concreta e abrangente de todo o sistema no qual se encontram os indivíduos, o desafio que deve ser enfrentado não tem paralelos na história. Pois o cumprimento dessa nova tarefa histórica envolve simultaneamente a mudança qualitativa das condições objetivas de reprodução da sociedade, no sentido de reconquistar o controle total do próprio capital - e não simplesmente das personificações do capital que afirmam os imperativos do sistema como capitalistas dedicados - e a transformação progressiva da consciência em resposta às condições necessariamente cambiantes.

Portanto, o papel da educação é soberano, tanto para a elaboração de estratégias apropriadas e adequadas para mudar as condições objetivas de reprodução, como para a automudança consciente dos indivíduos chamados a concretizar a criação de uma ordem social metabólica radicalmente diferente. É isso que se quer dizer com a concebida sociedade de produtores livremente associados. Portanto, é surpreendente que na concepção marxista, a efetiva transcendência da auto-alienação do trabalho seja caracterizada como uma tarefa inevitavelmente educacional (MÉSZÁROS, 2005, p. 65).

No contexto do neoliberalismo a educação e a escola são apresentadas para a sociedade como instrumento de integração e fundamental para a competitividade das economias na era da globalização. A educação nesse cenário procura dar ênfase nas capacidades e competências que cada pessoa deve adquirir no mercado educacional no intuito de atingir uma melhor posição no mercado de trabalho através da empregabilidade.

Este projeto político de educação para o mercado está ligado intimamente às práticas de ajuste impostas aos países "não desenvolvidos" ou "em desenvolvimento" dentro de um contexto de globalização e reestruturação produtiva. "A criação de uma força de trabalho altamente qualificada que atraia o capital deslocado para as economias dependentes de baixos salários. Educação e treinamento é, de acordo com esse ponto de 
vista, a principal cura para os males econômicos" (WOOD, 2003, p. 244245).

Sob os ditames de agências internacionais como o Banco Mundial, Comissão Econômica para América Latina e o Caribe (CEPAL), Organização das Nações Unidas para a Educação, a Ciência e a Cultura (UNESCO) e a Organização Internacional do Trabalho (OIT), a missão da educação é desenvolver habilidades básicas no plano do conhecimento, das atitudes e dos valores, produzindo competências para gestão da qualidade, para a produtividade e competitividade e, consequentemente, para a "empregabilidade".

De acordo com Hill (2003, p. 27), a escola, para o capital, através de seus profissionais, é um instrumento do sistema que deverá estar voltada para "o desenvolvimento da única mercadoria sobre a qual depende o sistema capitalista: a força de trabalho".

Segundo Chesnais e Sauviat (2005, p. 161), as redes de aprendizagem são dependentes de fontes de financiamento, da disponibilidade do capital para investimento, tanto privado como público, cujo financiamento público é alocado pelo orçamento governamental e pago por meio de impostos ou endividamento.

Para os autores supracitados, em razão das pressões por relacionamentos cada vez mais próximos com as empresas em nome da "competitividade", do desenvolvimento, o componente mais decisivo que apoia a inovação nas empresas seja o "sistema educacional de um país, no qual as despesas são sustentadas pelo Estado, autoridades locais e a população em geral" (CHESNAIS; SAUVIAT, 2005, p.164).

Os sistemas públicos de ensino, ao alocar recursos para a educação, fazem-no dentro dos procedimentos das finanças públicas. A administração dos recursos oriundos do financiamento da educação pública precisa ser entendida por critérios exteriores à educação escolar propriamente dita, ou seja, como parte integrante da política pública do Estado. O financiamento da educação é a interpelação entre a política econômica e a política educacional. 


\section{Considerações finais}

O corte epistemológico do materialismo histórico, é que um sistema teórico ele é revolucionário quando visa à "superação do processo social e psicológico de esvaziamento da individualidade humana pela alienação da estrutura da vida cotidiana de nossa sociedade bem como, a superação das condições objetivas que determinam esse processo de alienação" (ROSSLER, 2006, p. 289).

É preciso que as pesquisas educacionais caminhem em direção à reflexão teórica e filosófica, da análise crítica, coerente e consistente e do estudo sistemático. Promover a crítica da realidade, e não deixar se entreter com a sedução da aparência e da "superficialidade deslumbrada das ideias e dos fatos".

Para isso, se requer uma pesquisa em educação que não leve para assimilação de esquemas operatórios e a formação de hábitos miméticos, mas é para desencadear processos, a criação de situações problemáticas que estimulem a ação nas diferentes formas da realidade, em seus diferentes contextos territoriais.

Nesta perspectiva, a forma da realidade foi e continua sendo construída socialmente, sustentada em diferentes relações sociais, bem como, política e econômica, circunscrita em um modo de produção determinado, cujas formas definem os limites das práticas e das ações dos indivíduos e que as relações desenvolvidas em um determinado espaço social, em relação de sua forma organizativa de produção e poder são conflituosas e tensas pelo movimento de apropriação e expropriação.

Sendo assim, acreditamos que o método que adotamos não parte simplesmente da "quantidade dos dados empíricos disponíveis" de um dado fenômeno da realidade, mas de categorias e princípios que "regem a totalidade concreta". E que "as categorias de análise constitutivas da teoria", "nada mais é do que um reflexo que expressa o grau de consciência do homem em relação ao desenvolvimento material" (ALVES, 1996, p. 16). 


\section{Referências}

ALVES, Gilberto Luiz. Educação e história em Mato Grosso: 1719-1864. $2^{a}$ Ed. Campo Grande/MS: Editora UFMS, 1996.

ALVES, Gilberto. Universal e singular: em discussão a abordagem científica do regional. In: ALVES, G. Mato Grosso do Sul: o universal e o singular. Campo Grande: Editora UNIDERP, 2003. p. 17-29.

BOURDIEU, Pierre; CHAMBOREDON, Jean-Claude e PASSERON, JeanClaude. O Ofício de Sociólogo: Metodologia da pesquisa na sociologia. $5^{\text {a }}$ ed. Petrópolis, RJ: Vozes, 2004.

CAMPOS, R. F. Fazer mais com menos - a gestão educacional na perspectiva da Cepal e da Unesco. In: $28^{a}$ Reunião Anual da ANPEd. Caxambu, 2005. Disponível em:

http://www.anped.org.br/reunioes/28/inicio.htm. Acesso em: 02/06/2008.

CHESNAIS, F.; SAUVIAR, C. O financiamento da inovação no regime global de acumulação dominado pelo capital financeiro. In: Conhecimento, sistemas de inovação e desenvolvimento. Helena M. M. Lastres, José Cassiolato e Ana Arroio (organizadores) - Rio de Janeiro: Editora UFRJ/Contraponto, 2005.

ENGELS, Friedrich. A origem da família, da propriedade privada e do Estado. São Paulo: Global 1982.

FEDATTO, N.A.S.F. A História da Educação no Estado de Mato Grosso do Sul (1977-2007): contribuições para o estado da arte. da história da educação básica, pública, sul-mato-grossense (1977-2007) segundo duas perspectivas.

www.histedbr.fae.unicamp.br/acer_histedbr/.../ChRDyzUi.doc, acesso em 23/01/2011.

HILL, D. O neoliberalismo global, a resistência e a deformação da educação. In Currículo sem Fronteiras, v.3, n.2. p. 24-59. Jul/Dez, 2003. Disponível em http://www.curriculosemfronteiras.org.br Acesso: 10/05/2011.

LOWY, Michael. As aventuras de Karl Marx contra o Barão de Müchhausen: marxismo e positivismo na sociologia do conhecimento. $2^{\mathrm{a}} \mathrm{ed}$. São Paulo, Ed. Busca Vida, 1987.

MARX, Karl. La ideologia alemana. Montevideo: Ediciones pueblos unidos, 1968. 
Glosas Críticas Marginais ao artigo "O rei da Prússia e a reforma social. De um prussiano”. São Paulo: Expressão Popular, 2010. 1979. . Miséria de la filosofia. $7^{\mathrm{a}}$ ed. México: siglo veintiuno editores,

MARX, Karl; ENGELS, F . Manifesto do Partido Comunista. São Paulo, Cortez, 1998.

MÉSZÁROS, István. Educação para além do capital, São Paulo, Boitempo, 2005.

OLIVEIRA, Vitor Marinho. O Esporte Pode Tudo. In: MALINA, André e CESARIO, Sebastiana (Org.) Esporte: fator de integração e inclusão social? Campo Grande, UFMS, 2010.

REALE, Giovanni; ANTISERI, Dario. História da filosofia, 6v.; tradução de Ivo Storniolo; 1.ed. São Paulo: Paulus, 2006.

ROSSLER, João Henrique. Sedução e alienação no discurso construtivista. Campinas, SP: Autores Associados, 2006. ( Col. educação contemporânea ).

PAVIANI, Jayme. Conhecimento científico e ensino: ensaios de epistemologia prática. Caxias do Sul: Educs, 2006.

TONET, Ivo. Método Científico: uma abordagem ontológica. São Paulo, Instituto Lukács, 2013.

VIANNA,Luiz Werneck. Liberalismo e Sindicato no Brasil, Paz e Terra, Rio de Janeiro, 1976.

WOOD, Ellen Meikins. Democracia Contra o Capitalismo: A Renovação do Materialismo, Boitempo, São Paulo, 2005. 